\title{
Descemet's Stripping with Automated Endothelial Keratoplasty (DSAEK) in Patients with Black Diaphragm Intraocular (BDI) Lens
}

\author{
Hui-Jin Chen, Yan-sheng Hao and Jing Hong \\ Department of Ophthalmology, Peking University Third Hospital, Beijing,
}

China

\section{Introduction}

A stable anterior chamber is a crucial factor to DSAEK. In aniridic patients with BDI lens, the anterior and posterior segment has direct communication at the periphery of the BDI lens. Maintenance of the air bubble in the anterior chamber would be problematic. Pressure equilibrium must be established on both sides of the BDI lens before the air bubble is introduced into the anterior chamber.

Compared with traditional full-thickness keratoplasty, endothelial keratoplasty (EK) is a great breakthrough for the treatment of corneal endothelial disorders because this new technique maintains a more regular corneal anterior surface, preserves more corneal biomechanical tensile strength and provides more rapid visual rehabilitation. Descemet's stripping with automated endothelial keratoplasty (DSAEK) is currently most favored procedure of EK, in which the donor disc dissection was performed with an automated microkeratome that allows smoother interface and more accurate control of graft thickness.

A stable iris-lens diaphragm is essential to intraoperative donor unfolding and maintenance of air in the anterior chamber, and thus a critical factor for DSAEK. Although it was once considered as a relative contraindication, DSAEK has begun to be undertaken in patients in whom the iris-lens diaphragm was anatomically or functionally abnormal.1,2,3

In the past decade, patients with aniridia and aphakia/cataract were treated with black diaphragm intraocular (BDI) lens which is composed of a central optic surrounded by a black diaphragm and 2 haptics. This lens could alleviate the patients' symptom of glare and photophobia and increase vision. However, this BDI lens differs from the natural iris-lens diaphragm for more rigidity and less compliance. Besides, the chamber anterior to the BDI lens has direct communication with the vitreous cavity at the gap between the diaphragm and haptics of the lens. Difficulties may be encountered in maintaining the air bubble in the anterior chamber. Herein, we present 3 consecutive cases of bullous keratopathy with BDI lens who underwent DSAEK, the etiologies included 1 congenital aniridia and 2 traumatic iris loss.

\section{Case report}

\subsection{Case 1}

A 50-year-old man present with bullous keratopathy in his left eye. He had a history of left corneal laceration in 2000, and underwent black diaphragm intraocular (BDI) lens 
implantation in 2003. Ophthalmic examination revealed a linear corneal scar, the majority of iris was absent except the nasal remnants adhering to the corneal endothelium. Ultrasound biomicroscopy (UBM) showed that the BDI lens was in the right position. Preoperative bestcorrected visual acuity in the left was counting fingers, and the intraocular pressure (IOP)
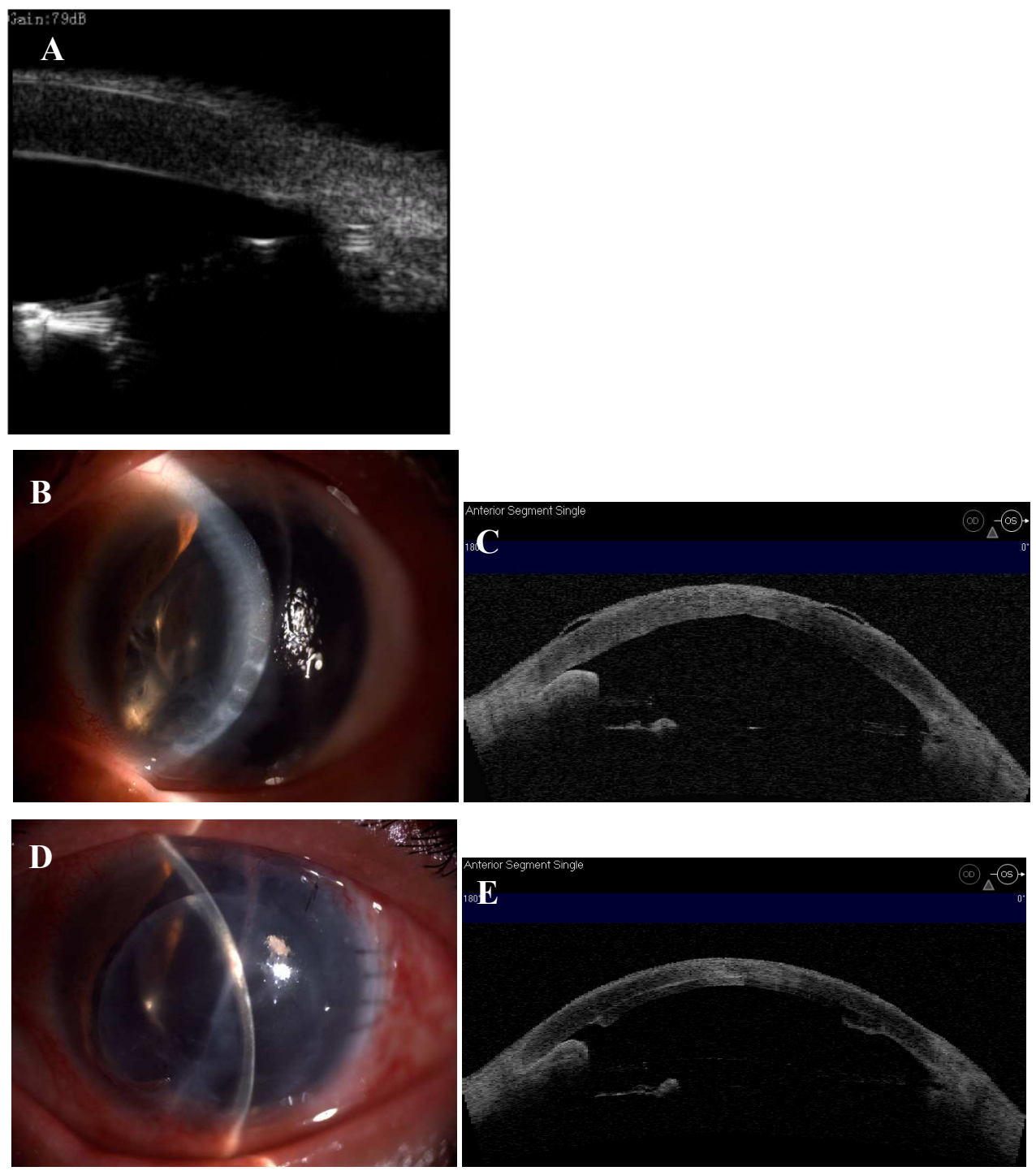

Fig. 1. (case 1) UBM shows that BDI lens is at the right position of ciliary sulcus (A).

Preoperative slit lamp photograph shows edematous cornea (B). AS-OCT shows bullea of the epithelium.The nasal iris remnant is adherent to the cornea (C). Postoperative slit lamp photograph (D) and AS-OCT (E) shows a well apposed graft. 
was controlled within normal limit with medication. DSAEK was uneventful. However, on the first postoperative day the upper part of the graft was observed detached and the air bubble was invisible in the anterior chamber. Graft reattachment surgery was performed. The eye was first inflated to the normal pressure with balanced salt solution (BSS) that was injected into both the vitreous cavity and the anterior chamber. After that, the anterior chamber was inserted with $0.15 \mathrm{ml}$ viscoelastic (Healon GV) followed by filtered air bubble. The patient was instructed to maintain a face-up position for at least 4 hours. The graft was successfully reattached after this procedure. Anterior segment optical coherence tomography (AS-OCT, Visante; Carl Zeiss Meditec, Dublin, California) showed a well apposed graft. The left eye increased to 0.3 . The IOP was normal postoperatively. But it rose to $43 \mathrm{mmHg}$ around one month postoperatively. It was controlled to normal by medically.

\subsection{Case 2}

A 49-year-old woman present with DSAEK in her left eye, as history of bilateral congenital aniridia and cataract and lens implantation in 2002. On examination, pendular nystagmus. Preoperative best-corrected visual acuity was 0.12 in the right and 0.1 in the left, and the IOP was $17 \mathrm{mmHg}$ in the right and $20 \mathrm{mmHg}$ in the left when using eye-drops. The left cornea
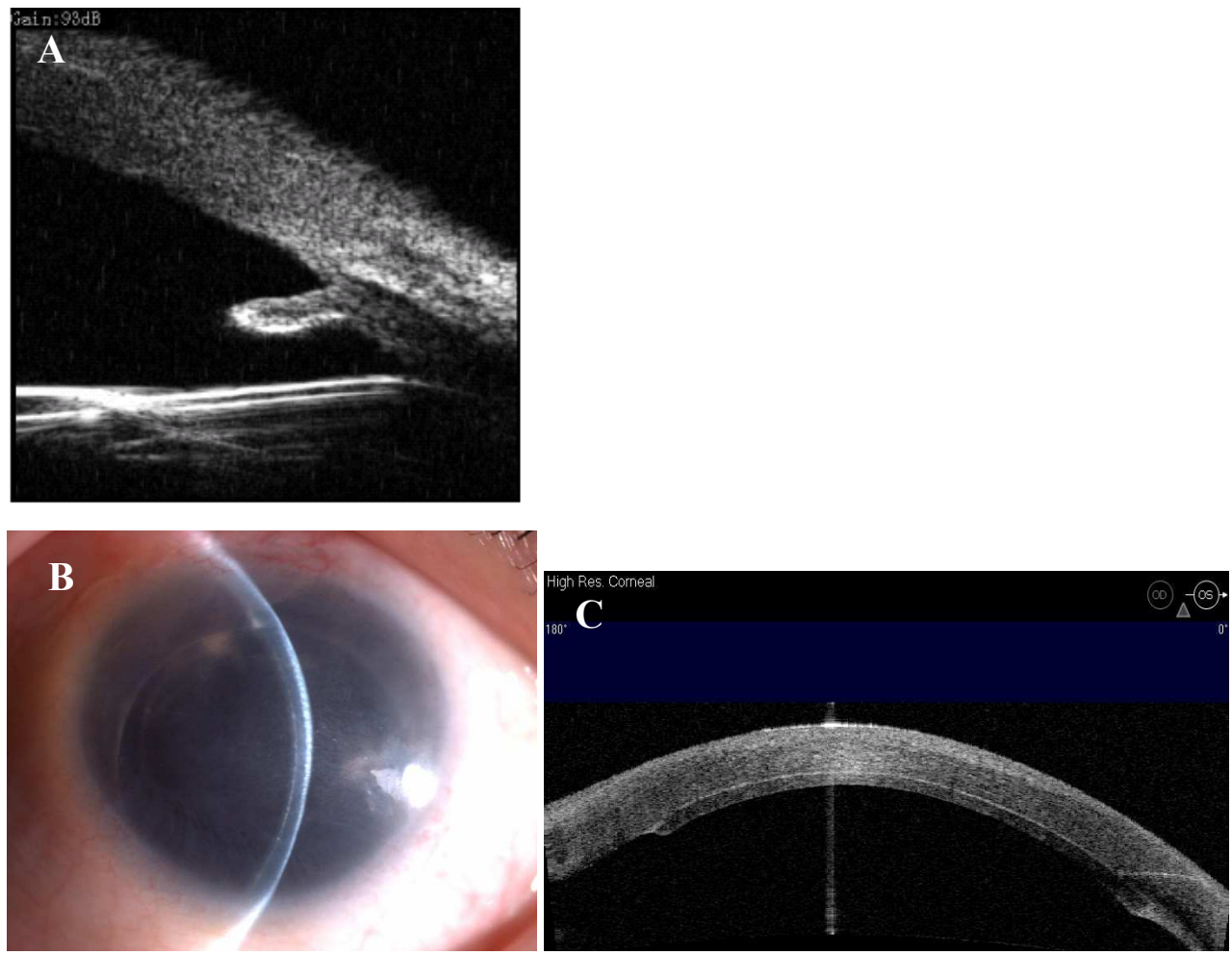

Fig. 2. (case 2) UBM shows iris remnants at periphery. The BDI lens is at the right position of ciliary sulcus (A). Postoperative slit lamp photograph (B) and AS-OCT (C) shows a well apposed graft. 
had a ground glass appearance. UBM showed that the BDI lens was in the right position. The lens was sutured. DSAEK was uneventful. 1 month after DSAEK, the patient suffered an ocular hypertony that couldn't be controlled by medication. Ciliary body photocoagulation was undertaken to lower the IOP. The last follow-up visit was 2 month after DSAEK, her IOP was $12 \mathrm{mmHg}$, and visual acuity was 0.12 .

\subsection{Case 3}

A 79-year-old man present with bullous keratopathy in his right eye. He underwent traumatic cataract extraction and BDI lens implantation in 2003. On examination, his bestcorrected visual acuity was hand motion in the right, and the IOP was within the normal limits without medication. DSAEK was performed using a neonate donor. The graft markedly contracted during the first postoperative week. Two months later, the patient received a second surgery to exchange the graft. No postoperative complications occurred this time. The last follow-up visit was 3 month after the second DSAEK, the visual acuity improved to 0.1 . IOP was good.

The DSAEK basic procedures were same with the reported by Terry. The implants was prepared by using a Moria (Antony, France) automated microkeratome and a Moria artificial chamber.
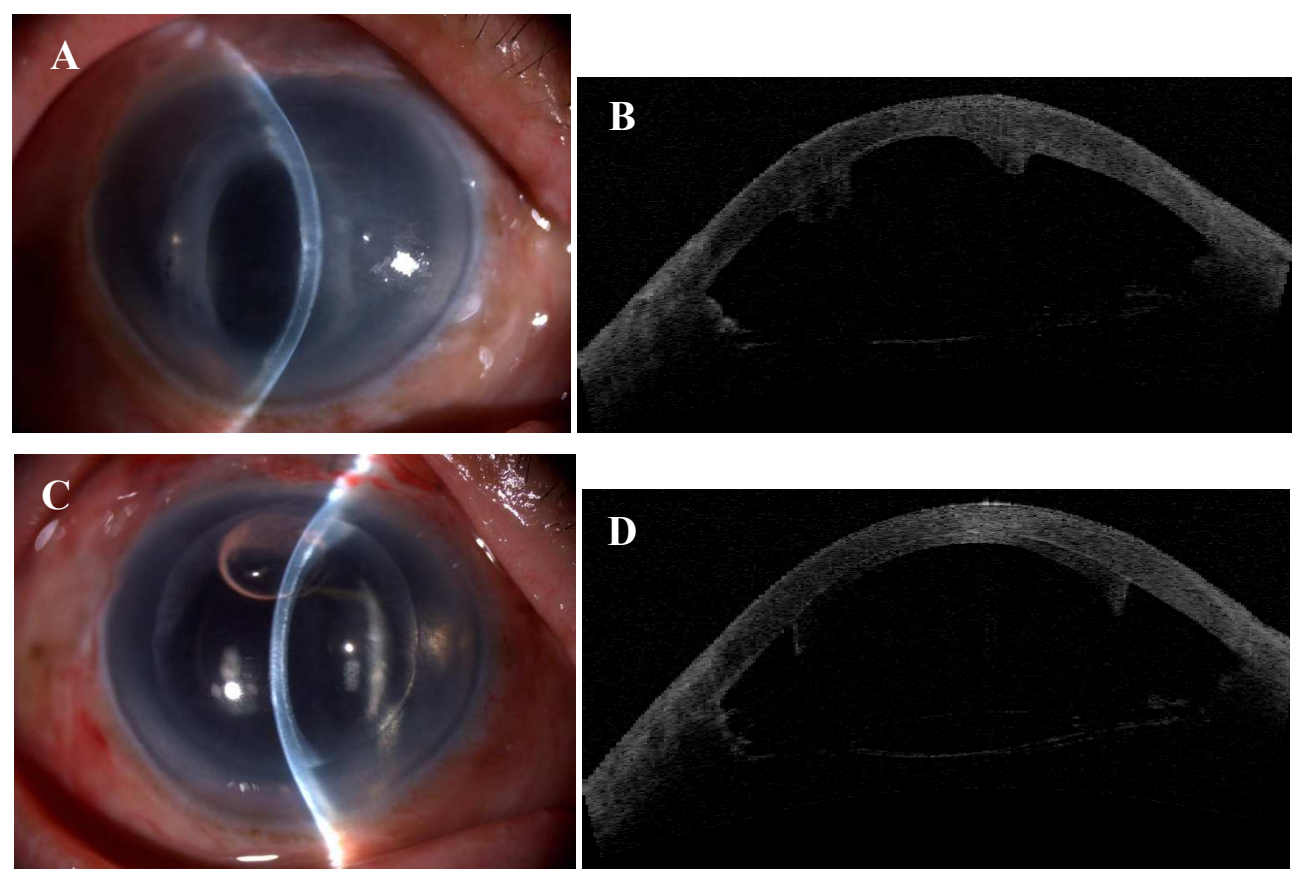

Fig. 3. (case 3) Slit lamp photograph (A) and AS-OCT (B) shows the donor tissue shrink during the first postoperative week. (C) and (D) shows the newly exchanged donor disc is well attached. 


\section{Discussion}

Most manipulations during the DSAEK surgery are performed in the anterior chamber. In addition, at the end of the surgery, air bubble is introduced into the anterior chamber to support the donor graft. Therefore, the stability of the anterior chamber is a critical factor in DSAEK. The natural iris-lens diaphragm is a barrier separating the anterior chamber from posterior vitreous cavity. Patients with anatomically or functionally anomalous iris-lens diaphragm are challenges to DSAEK. Small case series of DSAEK/DSEK were reported in patients with intraoperative floppy-iris syndrome, aphakic patients and aniridic aphakic patients.1,2,3 The results were largely favorable with some modification of the surgical technique. Bradley et al. described a suture-drag technique to minimize intraoperative donor endothelial trauma in patients with intraoperative floppy-iris syndrome. ${ }^{1}$ Price et al. used anchor suture securing the donor to the recipient to prevent the donor tissue from dropping down to the retina in aniridic aphakic eyes. ${ }^{2}$ However, since the main purpose of DSAEK is to improve vision, we think it should be more appropriate to correct aphakia and aniridia either prior to or at the same time with DSAEK surgery. Aniridic aphakic patients would benefit from BDI lens that could in some extent compensate optically the loss of iris and crystal lens. However, the BDI lens is not an ideal barrier to maintain a stable anterior chamber compared with the natural iris-lens diaphragm. There is gap between the haptics and the black diaphragm, especially in the traumatic cases without capsular remnants. Therefore, after a $5 \mathrm{~mm}$ incision was made in DSAEK, the pressure in the anterior chamber will decrease, thus it is unavoidable that the liquefied vitreous humor will go through the gap into the anterior chamber and the pressure of the posterior segment will decline. Anterior irrigation during graft insertion is not enough to compensate this occult vitrous loss. In the presence of pressure difference between the anterior and posterior segment, when the air bubble was injected into the anterior chamber, it would easily go back to the vitreous cavity postoperatively just like what we observed in case 1 in which the graft was found partially detached and the air bubble was totally disappeared on the first postoperative day. Therefore, when DSAEK is considered in an aniridic patient with BDI lens, we recommend that the pressure difference should be balanced first before the donor was unfolded by the air bubble.

Glaucoma is a common complication for both traumatic and congenital aniridia. In the traumatic eye, the trabecular meshwork could easily be jeopardized in the presence of extensive loss of iris tissue. Likewise, anomalous development of the anterior chamber angle in congenital aniridia could result in progressive IOP elevation. ${ }^{4}$ In addition, the prevalence of glaucoma will further increased after BDI lens implantation.5,6 It was ascribed to the continuous irritation of the haptics and the diaphragm to the uveal remnants in congenital aniridia, which may alter the blood-aqueous barrier, accelerating glaucoma progression. ${ }^{5}$ It was also proposed that the large size of the BDI lens may impair aqueous outflow by direct compression on the anterior chamber angle. ${ }^{6}$ In some cases the haptics of the lens were found not rest in the ciliary sulcus but in the anterior chamber angle. ${ }^{5}$ Therefore, use of type $67 \mathrm{G}$ BDI lens with smaller haptic diameter $(12.5 \mathrm{~mm})$ was recommend. ${ }^{6}$ Glaucoma was observed in two of our patients (case 1 and case 2) before DSAEK, but could be controlled medically. During the postoperative follow-up, case 1 had a temporary IOP rise, and case 2 experienced a persistent hypertony that was successfully treated with cyclophotocoagulation. In our case series, all three patients were implanted with 67G BDI lens, and the UBM prior to DSAEK surgery showed the haptics of the lens were not in 
contact with the trabecular meshwork. Therefore, we think angle compression by the haptics is not a major cause for IOP elevation in our cases. However, we do believe that glaucoma is an issue that deserves special attention when DSAEK is planned to be undertaken in aniridic cases with BDI lens. A well control of IOP preoperatively and close postoperative follow-up to monitor the IOP is recommended.

It is also essential to find out the main reasons for endothelial decompensation in these three cases. Trauma can cause endothelial loss. Congenital aniridia could also associate with endothelial deficiency, although the most common corneal change is limbal stem cell deficiency.7,8 Normally, the BDI lens was sutured to the ciliary sulcus, it should has no friction with the endothelium unless the BDI lens is decentered or displaced anteriorly.5,6 In our three patients, UBM showed that the BDI lens were in the right position, and the endothelial cell counts before BDI lens implantation were already lower than the normal value. We think that BDI lens did not contribute to endothelial cell loss in our three cases, and thus it was not necessary to remove the lens during DSAEK.

\section{References}

[1] Bradley JC, McCartney DL. Descemet's stripping automated endothelial keratoplasty in intraoperative floppy-iris syndrome: Suture-drag technique. J Cataract Refract Surg. 2007;33:1149-50.

[2] Price MO, Price FW Jr, Trespalacios R. Endothelial keratoplasty technique for aniridic aphakic eyes. J Cataract Refract Surg. 2007;33:376-9.

[3] Suh LH, Kymionis G, Culbertson WW, et al. Descemet's stripping with endothelial keratoplasty in aphakic eyes. Arch Ophthalmol 2008;126:268 -70.

[4] Grant WM, Walton DS. Progressive changes in the angle in congenital aniridia, with development of glaucoma. Trans Am Ophthalmol Soc. 1974;72:207-28.

[5] Reinhard T, Engelhardt S, Sundmacher R. Black diaphragm aniridia intraocular lens for congenital aniridia: Long-term follow-up. J Cataract Refract Surg. 2000;26:375-81.

[6] Implantation of the Black Diaphragm Intraocular Lens in Congenital and Traumatic Aniridia. Ophthalmology 2008;115:1705-1712

[7] Mackman G, Brightbill FS, Optiz JM. Corneal changes in aniridia. Am J Ophthalmol 1979;87:497-502.

[8] Ramaesh K, Ramaesh T, Dutton GN, Dhillon B. Evolving concepts on the pathogenic mechanisms of aniridia related keratopathy. Int J Biochem Cell Biol. 2005;37:547-57. 


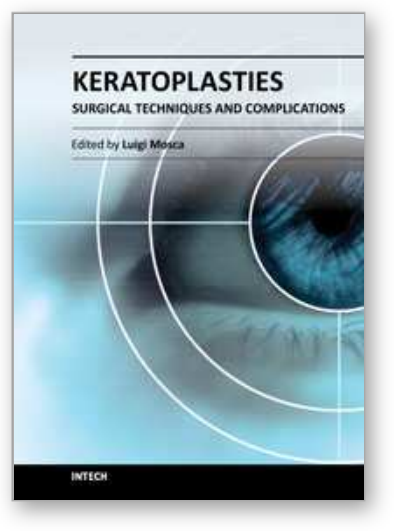

\author{
Keratoplasties - Surgical techniques and complications \\ Edited by Dr. Luigi Mosca
}

ISBN 978-953-307-809-0

Hard cover, 134 pages

Publisher InTech

Published online 18, January, 2012

Published in print edition January, 2012

In this book, the authors illustrate different therapeutic and surgical approaches to treating various corneal pathologies. This edition in electronic format allows universal access to everybody regardless of the time of day or setting, portability, and speed of information access. Such features show more feasibility for all readers and reduce the time necessary for research. This book will be a good tool for students as well as specialists working in the field of corneal transplantation, to improve their knowledge of treatment of corneal disease.

\title{
How to reference
}

In order to correctly reference this scholarly work, feel free to copy and paste the following:

Hui-Jin Chen, Yan-sheng Hao and Jing Hong (2012). Descemet's Stripping with Automated Endothelial Keratoplasty (DSAEK) in Patients with Black Diaphragm Intraocular (BDI) Lens, Keratoplasties - Surgical techniques and complications, Dr. Luigi Mosca (Ed.), ISBN: 978-953-307-809-0, InTech, Available from: http://www.intechopen.com/books/keratoplasties-surgical-techniques-and-complications/descemet-s-strippingwith-automated-endothelial-keratoplasty-dsaek-in-patients-with-black-diaphragm-

\section{INTECH}

open science | open minds

\section{InTech Europe}

University Campus STeP Ri

Slavka Krautzeka 83/A

51000 Rijeka, Croatia

Phone: +385 (51) 770447

Fax: +385 (51) 686166

www.intechopen.com

\section{InTech China}

Unit 405, Office Block, Hotel Equatorial Shanghai

No.65, Yan An Road (West), Shanghai, 200040, China

中国上海市延安西路65号上海国际贵都大饭店办公楼 405 单元

Phone: +86-21-62489820

Fax: +86-21-62489821 
(C) 2012 The Author(s). Licensee IntechOpen. This is an open access article distributed under the terms of the Creative Commons Attribution 3.0 License, which permits unrestricted use, distribution, and reproduction in any medium, provided the original work is properly cited. 